Chronic Obstructive Pulmonary Diseases:

Journal of the COPD Foundation

\title{
National COPD Readmissions Summit 2013: Integrating COPD into Patient-Centered Hospital Readmissions Reduction Programs
}

\author{
Jerry A. Krishnan, MD, PhD, ${ }^{1,2}$ Hélène A. Gussin, $\mathrm{PhD},{ }^{2}$ Valentin Prieto-Centurion, $\mathrm{MD},{ }^{2}$ \\ Jamie L. Sullivan, MPH, ${ }^{3}$ Farhan Zaidi, MD, ${ }^{2}$ Byron M. Thomashow, MD ${ }^{4}$
}

\begin{abstract}
About 1 in 5 patients hospitalized for exacerbations of chronic obstructive pulmonary disease (COPD) in the United States are readmitted within 30 days. The U.S. Centers for Medicare and Medicaid Services has recently expanded its Hospital Readmissions Reduction Program to financially penalize hospitals with higher than expected all-cause 30-day readmission rates following a hospitalization for COPD exacerbation. In October 2013, the COPD Foundation convened a multi-stakeholder National COPD Readmissions Summit to summarize our understanding of how to reduce hospital readmissions in patients hospitalized for COPD exacerbations. Over 225 individuals participated in the Summit, including patients, clinicians, health service researchers, policy makers and representatives of academic health care centers, industry, and payers. Summit participants recommend that programs to reduce hospital readmissions: 1) Include specific recommendations about how to promote COPD self-management skills training for patients and their caregivers; 2) Adequately address co-existing disorders common to COPD in care plans during and after hospitalizations; 3) Include an evaluation of adverse events when implementing strategies to reduce hospital readmissions; and 4) Develop a strategy (e.g., a learning collaboratory) to connect groups who are engaged in developing, testing, and implementing programs to reduce hospital readmissions for $C O P D$ and other conditions.
\end{abstract}

Abbreviations: Centers for Medicaid and Medicare, CMS; Hospital Readmissions Reduction Program, HRRP; Patient-Centered Outcomes Research Institute, PCORI; COPD Outcomes-based Network for Clinical Effectiveness and Research Translation, CONCERT; International Classification of Disease, Ninth Revision, ICD-9; Society of Hospital Medicine, SHM; Project Better Outcomes by Optimizing Safe Transitions, BOOST; Project Re-Engineered Discharge, RED; quality improvement, QI; Primary Care Resource Centers, PCRC; Recovering Obstructive Lung Disease, ROLD

Funding Support: The COPD Readmissions Summit was supported in part by the American Association for Respiratory Care and the Rhode Island State Nurses Association. The Summit webcast was sponsored by Sunovion.

Date of Acceptance: October 2, 2014

Citation: Krishnan JA, Gussin HA, Prieto-Centurion V, Sullivan JL, Zaidi F, Thomashow BM. National COPD Readmissions Summit: Integrating COPD into patient-centered hospital readmissions reduction programs. J COPD F. 2015;2(1): 70-80. doi: http://dx.doi. org/10.15326/jcopdf.2.1.2014.0148

1 Population Health Sciences Program. University of Illinois Hospital \& Health Sciences System, Chicago

2 Department of Medicine, Section of Pulmonary, Critical Care, Sleep and Allergy Medicine, University of Illinois at Chicago

3 COPD Foundation, Washington, DC

4 Department of Medicine, Division of Pulmonary, Allergy and Critical Care Medicine, Columbia University Medical Center, New York, New York

\section{Address correspondence to:}

Jerry A. Krishnan, MD, PhD

University of Illinois Hospital \& Health Sciences System

Medical Center Administration Building.

914 S. Wood Street, MC 973

Chicago, IL 60612

T: (312) 413-0637 | F: (312) 413-3099

jakris@uic.edu 


\section{Introduction}

Chronic obstructive pulmonary disease (COPD) is a progressive lung disorder characterized by persistent airflow obstruction and chronic respiratory symptoms in response to inhaled cigarette smoke or other irritants or a deficiency of alpha-1-antitrypsin. COPD is the third leading cause of death in the United States. ${ }^{1}$ There are approximately 700,000 hospitalizations with the principal diagnosis of COPD in the United States each year, with 1 in 5 readmitted within 30 days. $^{2-5}$ About half of the estimated $\$ 50$ billion in annual health care expenditures for COPD has been attributed to costs associated with hospitalizations for COPD exacerbations. $^{6-8}$

In 2012, the Centers for Medicare and Medicaid Services (CMS) launched the Hospital Readmissions Reduction Program (HRRP) to reduce the risk of hospital readmissions in patients hospitalized for acute myocardial infarction, pneumonia, or heart failure. In 2014, the CMS HRRP was expanded to include hospitalizations for COPD exacerbations. The CMS HRRP uses financial penalties to motivate hospitals to develop, test, and implement quality improvement programs to reduce avoidable hospital readmissions within 30 days of hospital discharge. The CMS HRRP financial penalties can be as high as 3\% of hospitalspecific Medicare payments for all discharges, not only payments related to the excess readmissions.

In October 2013, the COPD Foundation convened a multi-stakeholder National COPD Readmissions Summit to discuss readmissions in patients hospitalized for COPD exacerbations and the potential implications of adding COPD as a penalty-sensitive condition for the CMS HRRP. In this report, we summarize the discussions and recommendations from this Summit.

\section{Participants in the National COPD Readmissions Summit}

The COPD Foundation established a planning committee to identify potential speakers (Table 1 ). The Planning Committee invited representatives of several evidence-based programs designed to reduce hospital readmissions (Project Re-Engineered Discharge, Transitional Care Model, The Care Transitions Program, and Project Better Outcomes by Optimizing Safe Transitions). ${ }^{9-12}$ The Planning Committee also invited experts on the HRRP and interventions to reduce hospital readmissions in patients with COPD exacerbations. A representative of the Patient-Centered Outcomes Research Institute (PCORI) was invited to discuss the role of PCORI in funding studies addressing the expressed needs of patients and caregivers regarding hospital readmissions.

The workshop included in-person and online participants, who were encouraged to pose questions to the speakers. Over 225 participants attended the National COPD Readmission Summit, representing over 65 organizations. A diverse group of individuals participated in the Summit, including patients, clinicians, health service researchers, policy makers and representatives of academic health care centers, industry (pharmaceutical, durable medical equipment), and payers.

\section{Epidemiology of Readmissions in Patients With COPD Exacerbations}

The quality of care for patients hospitalized for COPD exacerbations varies, as does the risk of readmissions and mortality following hospital discharge in this population. ${ }^{8,13,14}$ In a study published in 2006, patients hospitalized for COPD exacerbations received only about $50 \%$ of the care recommended by guidelines. ${ }^{15}$ In a subsequent study conducted by the multicenter National Heart Lung and Blood Institute COPD Outcomes-based Network for Clinical Effectiveness and Research Translation (CONCERT), gaps in guideline-recommended care were most evident for instructing patients about how to use respiratory inhalers (approximately 20\% received instruction about use of respiratory inhalers, range $0 \%$ to $85 \%$ across 6 sites) and providing a post-discharge appointment for follow-up care (50\% had a post-discharge appointment prior to hospital discharge, range $20 \%$ to $80 \%$ across 6 sites). ${ }^{13}$

Analyses of billing data from over 190,000 hospitalizations in 15 states in the United States indicate that the all-cause (i.e., for any reason) 30-day readmission rate is $20.5 \%$ (with considerable variation across hospitals). Only about 1 in 3 of such readmissions are related to COPD. ${ }^{16}$ The majority of readmissions at 30 days appear to be related to deteriorations in co-existing conditions including cardiac, renal, and gastrointestinal disease, as well as concurrent infections (e.g., pneumonia). ${ }^{16}$ These findings suggest the need for adequately addressing co-existing conditions in the hospital and in the post-hospital period.

Among patients hospitalized for COPD exacerbations, 


\section{Table 1. Speakers at the COPD Foundation 2013 Readmissions Summit}

\section{Speakers \\ Name}

\section{Organization}

\section{Role/Topic}

Jalisa Bell
The Coordinating Center

(Baltimore, MD)

Co-Presenter: The Care Transitions Program

Presenter: PCORI Perspective

$\begin{array}{ll}\text { Chad Boult, MD, MPH, MBA } & \begin{array}{l}\text { Johns Hopkins Bloomberg School } \\ \text { of Public Health (Baltimore, MD) }\end{array}\end{array}$

Brian Carlin, MD

Drexel University \& Allegheny

General Hospital (Pittsburgh, PA)

Presenter: Overview of 30 Day Hospital

Readmission Statistics Related to COPD

Thomas Kallstrom, RRT

American Association for

Respiratory Care (Dallas, TX)

Panel Chair. Session: Keynote Addresses

Keith Kanel, MD

University of Pittsburgh \& Pittsburgh

Regional Health Initiative (Pittsburgh, PA)

Presenter: Research and Demonstration Projects

Addressing COPD Related Hospital

Readmissions; Community Based Demonstration

\& Research Projects

Jerry Krishnan, MD, PhD $\quad$ University of Illinois Hospital and Health

Sciences System (Chicago, IL)

Panel Co-chair. Session: Developing a Safe and Effective Hospital Readmissions Program with Patients with Multiple Chronic Conditions: COPD as a Poster Child.

Presenter: Research and Demonstration Projects

Addressing COPD-Related Hospital Readmissions;

Peer Reviewed Published Evidence

Presenter: Researcher Perspective

\begin{tabular}{l|l|l}
\hline Peter Lindenauer, MD, MSc & Baystate Medical Center (Springfield, MA) & Presenter: Overview of COPD Measures \\
\hline Phyllis Madachy & The Coordinating Center (Baltimore, MD) & Co-Presenter: The Care Transitions Program
\end{tabular}

Suzanne Mitchell, MD

(unable to attend, but

Boston University (Boston, MA)

Presenter: Project RED (Re-Engineered Discharge)

presentation was distributed

to Summit attendees)

\begin{tabular}{l|l}
\hline Mary Naylor, PhD, RN & $\begin{array}{l}\text { University of Pennsylvania } \\
\text { (Philadelphia, PA) }\end{array}$ \\
\hline
\end{tabular}

Jill Ohar, MD

Wake Forest Baptist Health

(Winston-Salem, NC)

Byron Thomashow, MD

Columbia University Medical Center

(New York, NY)

John Walsh

COPD Foundation (Washington, DC)

Mark Williams, MD

Northwestern University (Chicago, IL), now

at University of Kentucky (Lexington, KY)

Presenter: The Transitional Care Model

Panel Chair. Session: Fitting COPD into

National Hospital Readmission Reduction Models

Presenter: Major Determinants of COPD-Related 30 Day Hospital Readmissions

Panel Co-chair. Session: Developing a Safe and Effective Hospital Readmissions Program with Patients with Multiple Chronic Conditions:

COPD as a Poster Child

Presenter: Patient Perspective

Presenter: Major Determinants of COPD-Related 30 Day Hospital Readmissions 
the risk of 30-day readmissions is higher among patients living in areas with lower income (1.4\% absolute risk increase in patients living in the lowest versus highest quartile of household income) and among blacks (4\%, $2.7 \%$, and $2.6 \%$ higher compared to Asians/Pacific Islanders, Hispanics, and whites, respectively). ${ }^{16}$ These findings suggest that reducing hospital readmissions will require not only improving access, quality, and coordination of care post-discharge, but also resources linked to socioeconomic status (e.g., affordability of out-of-pocket costs of prescription medications; availability of transportation to appointments after hospital discharge; Table 2). These considerations highlight the disproportionate challenges that hospitals serving vulnerable patient populations will face when implementing programs to reduce hospital readmissions.

\section{Table 2. Risk Factors for Hospitalizations or Readmissions}

Risk Factor

References

(examples)

Clinical Factors

Disease severity, co-morbidities, post-hospital syndrome,

access to post-hospital care

$(17-25)$

Under-treatment

Pharmacologic Therapy Medication prescription and adherence, misuse of inhaler, non-adherence to supplemental $\mathrm{O}_{2}$

(26-37)

Pulmonary rehabilitation

Non-pharmacology

Smoking cessation, influenza vaccination

$(39-47)$

Prevention

Homelessness, food insecurity, substance abuse, lack of

$(48-50)$

Socioeconomic Resources

transportation

\section{The Five Hospital Readmissions Reductions Program Penalty- Sensitive Conditions}

In October 2012, the CMS HRRP began imposing financial penalties for hospitals with greater than expected all-cause readmission rates in patients hospitalized for 3 conditions - acute myocardial infarction, heart failure, and pneumonia. Beginning October 2014, CMS expanded its HRRP to also include hospitalizations for COPD exacerbations and hospitalizations for elective total hip or knee arthroplasty. ${ }^{51}$ All unplanned readmissions that occur within 30 days of hospital discharge, even those unrelated to the initial hospitalization, are included in the calculation of the 30-day readmission rate. Planned readmissions (e.g., for bronchoscopies that are scheduled to take place over 2 or more different hospitalizations) do not contribute to the 30-day readmissions rate. The CMS model for establishing the hospital-specific expected 30-day readmission rate adjusts for both hospital-level and patient-level confounders (age, comorbidities). Of note, race and other factors such as socioeconomic status are not included in the modeling, which is of particular concern since several studies have documented the role of socioeconomic resource-related factors in the risk of excess readmissions.

The penalties are expected to be up to approximately $1 \%$ for all CMS payments for hospital discharges in FY 2013 (October 1, 2012 to September 30, 2013), approximately 2\% in FY 2014 (October 1, 2013 to September 30, 2014), and approximately $3 \%$ in FY 2015 (October 1, 2014 to September 30, 2015). More details about the calculations can be found on the CMS HRRP website. ${ }^{51}$ For FY 2014, more than two-thirds of the almost 3500 hospitals nationwide that are subject to the HRRP will be penalized, with 15 institutions 
expected to receive the full $2 \%$ penalty.

\section{Including COPD in the Hospital Readmissions Reduction Program : The Upsides and Downsides}

There are multiple benefits supporting the inclusion of COPD in the CMS HRRP. ${ }^{52}$ Considering the growing clinical and financial impacts of COPD in the United States, many consider this new focus on COPD long overdue. Inclusion of COPD in the CMS HRRP has given hospitals a financial incentive to improve the care and outcomes of hospitalized patients with COPD exacerbations. In January 2013, CMS also introduced new billing codes for transitional care management, which could assist hospitals and clinicians in off-setting costs of developing and implementing strategies to improve care and outcomes after hospital discharge. ${ }^{53}$ Additionally, the all-cause 30-day readmissions rate following COPD exacerbations could serve as an easy to measure key performance indicator for cross-hospital comparisons by patients, caregivers, and payers. However, use of 30-day all cause readmission rates after hospitalization as an accountability measure is also problematic. Of particular concern is the lack of a validated algorithm with high sensitivity and specificity using International Classification of Disease, Ninth Revision (ICD-9) codes to identify hospitalization for COPD exacerbations, ${ }^{54}$ lack of evidence that decreasing readmissions improves outcomes (e.g., unintentional consequences include higher out-of-hospital mortality rates), and uncertainty regarding the preventability of readmissions. ${ }^{55}$ There are other limitations to the use of the 30-day CMS readmissions measure. The methods used to calculate the expected readmission rate (which is used to determine if the 30 -day readmissions rate is excessive) does not account for socioeconomic resources, which could adversely affect safety-net hospitals that provide a disproportionate share of care to patients with low socioeconomic resources. Financial penalties to safety-net hospitals could further diminish resources available to provide care to vulnerable populations. Also, the 30-day readmissions measure linked to 5 penalty-sensitive condition is susceptible to gaming - theoretically, hospitals could use diagnosis codes that avoid identifying the hospitalization as one for a penalty sensitive condition in patients at high-risk for a readmission. ${ }^{52}$

\section{Evidence-Based Programs to Reduce Hospital Readmissions}

\section{General (Not Disease-Specific) Interventions}

Much of the emphasis on reducing hospital discharge has been on the use of a bundle of medical interventions to improve the quality of hospital-based care and coordination of care with providers in the ambulatory setting. The care practices within the bundles include provider level interventions to increase adherence to evidence-based clinical practice guidelines (e.g., use of checklists), medication reconciliation, patient education, and arranging a follow-up visit with ambulatory providers and providing discharge summaries to improve hand-offs between hospital and ambulatory-based providers. A number of such evidence-based programs exist, including the Society of Hospital Medicine's (SHM) Project Better Outcomes through Optimizing Safe Transitions (BOOST), ${ }^{12}$ Project Re-Engineering Discharge (RED), ${ }^{9,56}$ Care Transitions Intervention, ${ }^{11,57-59}$ and the Transitional Care Model. ${ }^{10,60,61}$

BOOST engages a hospital-based multi-disciplinary quality improvement (QI) team to enhance the discharge process. ${ }^{12,62-64}$ Members of the QI team are typically clinical and administrative leadership of the hospital, including nurses, case managers, social workers, physicians, pharmacists, QI analysts, information technology staff, administrative staff and outpatient providers. A BOOST mentor identified by SHM works with the hospital-based QI team to review the development and use of a universal discharge checklist to (1) reconcile medications; (2) educate patients and caregivers about diagnosis, prognosis, self-care requirements, action plan, medication and side effects, using teach back; (3) establish phone contact with the patient by a nurse or pharmacist (or less commonly, a physician); and (4) establish phone or other communication with the ambulatory care provider to arrange a "warm" hand-off. BOOST recommends a phone call with the patient within 72 hours of discharge to assess health status, promote adherence to the treatment plan, and remind about follow-up, and to communicate the discharge plan and any update to the plan via phone to the ambulatory provider. BOOST does not include home visits. Data from 11 hospitals which implemented 1 or more Project BOOST tools, demonstrated an absolute 30 -day readmission reduction of $2 \%$ and a relative reduction of $13.6 \%$. $^{65}$ 
Project Red was developed at Boston University Medical Center to improve patient safety and reduce hospital readmission rates. ${ }^{9,56}$ The RED intervention is founded on 12 discrete, mutually-reinforcing components, such as language assistance, making appointments and plans for follow-up care, organizing post-discharge services (e.g., medical equipment), reviewing medication prescriptions, educating patients about their diagnosis, medications, and action plan, calling patients within 72 hours of discharge by a discharge educator or other member of the clinical staff to reinforce the discharge plan, and facilitating communication with ambulatory providers. As with Project BOOST, Project RED does not include home visits. More than 500 hospitals, in 49 states and 9 countries, have downloaded the Project RED toolkit and nurse training manual. In a clinical trial of over 700 patients, patients assigned to Project RED (versus usual care) had a significantly lower rate of emergency department visits and hospitalizations within 30 days (incidence rate ratio $0.7, P=0.009) .{ }^{56}$ Implementation of Project RED components in another setting was associated with a reduction of readmission rates (relative reduction: $36 \%$ at 30 days, compared to historical data). ${ }^{66}$

The Transitional Care Model targets older adults with complex needs transitioning from an acute care setting to their home or other care setting, and aims to prepare patients and family caregivers to more effectively manage changes in health associated with multiple chronic illnesses. ${ }^{10,60,61,67,68}$ A nurse serves as the primary care coordinator during the transition out of the hospital (Transitional Care Nurse) to coordinate individualized, patient-centered, multidisciplinary care that includes the following key elements: regular home visits for an average of 8 weeks after discharge, telephone support, engagement and education of patient and family, and communication between patient, caregivers, and health care providers, with emphasis on long term positive outcomes. Results of randomized clinical trials indicate that patients to the Transitional Care intervention have fewer readmissions (average relative reduction across studies: $45 \%$ at 90 days, $46 \%$ at 180 days, $36 \%$ at 12 months), fewer total days readmitted, lower mortality, and improved quality of life and patient satisfaction after discharge than patients receiving usual care. ${ }^{61,67,68}$

The Care Transition Program is a 4-week program during which patients with complex care needs are supported by a coach (often a nurse practitioner or nurse skilled in geriatrics) and learn self-management skills to ensure their needs are met during the transition from hospital to home. ${ }^{11}$ The program involves a predischarge visit in the hospital, a post-discharge home visit, and up to 3 follow-up phone calls at home. The program focuses on 4 concepts: (1) medication selfmanagement, (2) use of a dynamic patient-centered record, (3) primary care and specialist follow-up, and (4) knowledge of red flags (indication that condition is worsening and how to respond). ${ }^{69}$ Studies with randomized controlled trial and quasi-experimental designs demonstrate that the program reduces allcause readmission rates at 30 days (relative reduction approximately 30\%) and 90 days (approximately $25 \%) .{ }^{57,58}$ The model has been adopted by 944 organizations, $20 \%$ of which are hospitals; out of the 102 communities under the CMS's Community-Based Care Transitions Program, 77 are using Care Transitions Intervention. ${ }^{11}$

In summary, these 4 programs can help to reduce unplanned readmissions by promoting adherence to evidence-based clinical practice guidelines, medication reconciliation, promoting patient self-management skills, and facilitating hand-offs during the transition from hospital to ambulatory-based care. BOOST, Project RED, Care Transitions Model, and the Transitional Care Model all include a phone call after discharge to assess adherence and complications. The Care Transitions Intervention and the Transitional Care Model also include nurse-led home visits to extend the period of hospital-based care into patients' homes.

However, none of these programs include interventions-specific to patients with COPD, such as how to teach self-management skills unique to patients with lung disease (e.g., inhaler technique; use of supplemental oxygen, participation in pulmonary rehabilitation) or addressing co-existing conditions that commonly complicate the management of patients with COPD (e.g., how to differentiate dyspnea from heart failure versus worsening COPD; how to address adverse effects of medications used to treat COPD exacerbations on co-existing conditions). While patients with COPD were included in the published studies evaluating the 4 programs, results were not presented stratified by diagnosis at the index hospitalization, so it is unclear if the overall intervention effects were also observed in patients hospitalized with COPD exacerbations. 


\section{Interventions Specific to Patients With COPD Exacerbations}

Systematic Review of Published Literature

A recent systematic review ${ }^{70}$ identified 5 randomized clinical trials evaluating interventions to reduce readmissions following COPD exacerbations. ${ }^{71-75}$ These trials examined a range of different interventions, including discharge planning, disease education, health counseling, inhaler use teaching, development of an action plan, smoking cessation counseling, assessment of comorbidities, referral to pulmonary rehabilitation, use of a transition navigator, and follow-up home and/or telephone-based visits after discharge. Each study examined a different subset of the interventions above. Two of the 5 trials ( 1 conducted in Canada and 1 conducted in Spain and Belgium) showed a decrease in all-cause readmission over 12 months in the intervention group vs. comparator group (mean number of hospitalizations per patient: $1.0 \mathrm{vs}$. 1.8, $P=0.01$; percentage hospitalized: $45 \%$ vs. $67 \%$, $P=0.028$, respectively). ${ }^{72,74}$ The only clinical trial conducted in the United States found a greater than 2 -fold higher risk of mortality in the intervention group ( $17 \%$ vs. $7 \%, P=0.003$ ), but no significant difference in readmissions. ${ }^{71}$ The other 2 trials failed to detect differences in readmission rates between groups. There was substantial heterogeneity in the design, measurement, and reporting of study results, precluding a formal meta-analysis. None of the trials were designed to examine the effects of care transition strategies on 30day readmission rates; all focused instead on outcomes at 6 or 12 months. This review concluded that there is inadequate information to recommend COPD-specific interventions that can be used to reduce the risk of 30day readmissions.

\section{Unpublished Experience}

Various institutions are implementing strategies to reduce readmissions in patients hospitalized for COPD exacerbations. The Pittsburgh Regional Health Initiative in Pennsylvania conducted one of the nation's first regional collaboratives of medical, business and civic leaders organized to address health care safety and quality improvements. ${ }^{76}$ In Phase 1 , the program involved using an inpatient COPD nurse care manager to coordinate the care of patients with COPD upon discharge. To account for the significant overlap between the patients hospitalized with COPD and/or heart failure, the program evolved to create Primary Care Resource Centers (PCRC) in Phase 2. In Phase 2, the intervention involves a pharmacist for medication reconciliation, motivational interviewing, high-hazard medication focus and phone calls to patients within 72 hours of discharge, and nurse care managers to engage and educate patients and caregivers about self-management, conduct analysis of root cause for patients who are readmitted, and coordinate care with ambulatory providers. The program includes a home visit within 7 days of discharge and longitudinal care coordination. Compared to the period before implementation of the Phase 2 intervention, the post-implementation period was associated with a significant reduction in all-cause 180 -day readmission rates (relative reduction approximately $47 \%$ ). With the success of this first center, the health system received a $\$ 10.4$ million award from the CMS Innovation Center to create 6 more PCRCs at community hospitals in Pennsylvania and West Virginia from 2012 to 2015.

The Jesse Brown Veterans Affairs Hospital in Chicago, Illinois implemented a Recovering Obstructive Lung Disease (ROLD) post-discharge clinic in 2013. The ROLD clinic consists of 3 outpatient visits over a 4-week period, with the first visit scheduled within 1 week of hospital discharge. The patient's first clinic visit is scheduled by the discharge team, prior to the patient's discharge from the hospital. The ROLD clinic is built on an integrated care clinic model, involving a team of physicians, nurses and nurse practitioners, palliative care specialists, social workers, and pharmacists. Key elements of the ROLD clinic include (1) a standardized history and physical examination, use of validated tools to assess patient-reported health (COPD Assessment Test), spirometry to confirm the COPD diagnosis and classify COPD severity, and evaluation of supplemental oxygen requirements at sleep, rest, and activity; (2) literacy-appropriate education (general disease education, trigger management, inhaler technique teaching, use of supplemental oxygen equipment); (3) optimization of medical therapy for COPD and medication reconciliation; (4) smoking cessation advice and referral to a smoking cessation clinic; and (5) coordination of referrals to pulmonary rehabilitation programs and other follow-up care. Compared to the 12 months prior to the ROLD clinic, the all cause 30day readmissions rate for patients hospitalized with COPD exacerbations has dropped 5\% (from 19\% to 
$14 \%)$ according to a quality improvement report developed by Nina Bracken, APN, who provides care in the ROLD clinic.

\section{Figure 1.}

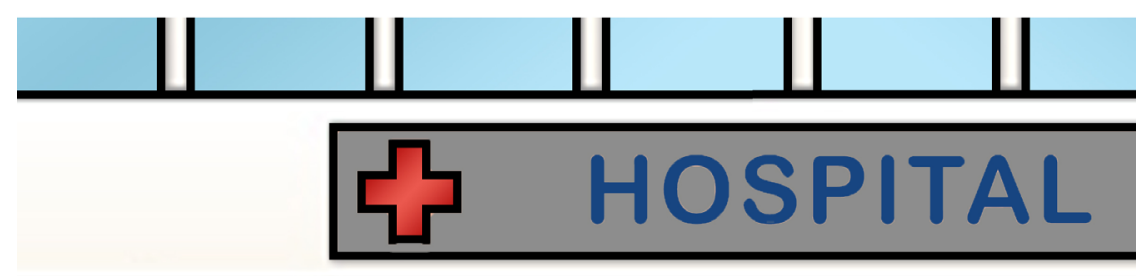

\section{Summary and Recommendations From the Summit}

The COPD Readmissions Summit highlighted the significant implications of the recently expanded CMS efforts to reduce the risk of all-cause readmissions within 30-days of hospital discharge. Although some existing transitions of care programs have been successful at reducing all-cause readmissions, the applicability of such programs to patients with COPD exacerbations is unclear. Patients recovering from COPD exacerbations need interventions to promote self-management

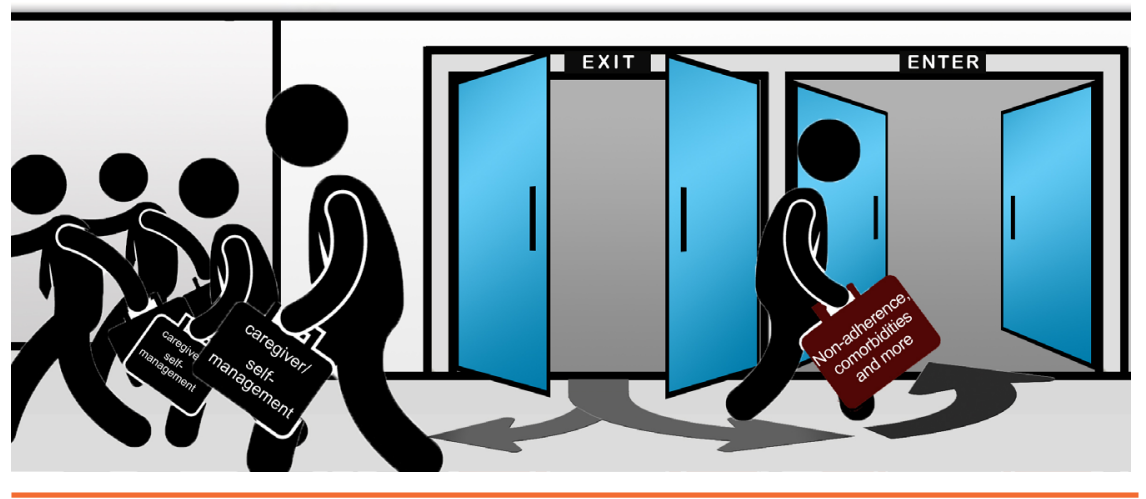
skills specific to COPD, address common co-existing clinical conditions that complicate COPD management, and coordinate care with ambulatory providers (Figure 1.) There is a surprising paucity of published evidence to guide clinicians and hospital administrators about how to safely avoid hospital readmissions in patients hospitalized for COPD exacerbations. The methods employed by the Pittsburgh Regional Health Initiative are promising; an evaluation when such strategies are scaled-up to other settings is needed. Discussions at the COPD Readmission Summit led to the following recommendations:

1) Programs to reduce hospital readmissions should include efforts to promote patient self-management skills specific to COPD, including appropriate use of medications (e.g., inhaler devices, supplemental oxygen), smoking cessation, and pulmonary rehabilitation. A rigorous evaluation of different approaches, including engaging caregivers, peers, and community health workers is needed.

2) Patients hospitalized with COPD exacerbations commonly have several clinically significant co-existing chronic and acute conditions (e.g., cardiovascular disease, pneumonia and mental health disorders). Results of studies suggest that co-existing disorders contribute to hospital readmissions more often than does a respiratory deterioration due to COPD. Strategies to reduce hospital readmissions in this population therefore need to adequately account for co-existing disorders during and after hospitalization.

3) Efforts to reduce hospital readmissions may be harmful. The only study conducted in the United

States demonstrated excess risk of death in patients assigned to a comprehensive care management plan. ${ }^{71}$ This observation highlights the need for appropriate monitoring of adverse events (including readmissions to other hospitals; out-of-hospital deaths) when implementing strategies to reduce hospital readmissions in patients recovering from COPD exacerbations.

4) A variety of hospital readmissions reduction programs are being implemented across the United States. A strategy to connect groups who are engaged in developing, testing, and implementing programs to reduce hospital readmissions is needed. The COPD Foundation has established a learning collaboratory to share best practices and to identify opportunities to inform the development of multicenter studies.

\section{Acknowledgements}

The authors thank the COPD Foundation staff for their assistance in convening the National COPD Readmissions Summit and preparing this article. The authors acknowledge that a freelance writer was engaged to assist in compiling information and notes to be used in the creation of this manuscript.

\section{Declaration of Interest}

VP-C and FZ are supported by an institutional National Institutes of Health T32 institutional training grant (2T32HL082547), JK and HAG are supported in part by Patient-Centered Outcomes Research Institute contracts IH-12-11-4365, CE 1304-6490, and PPRN 1306-04748. 


\section{References}

1. Centers for Disease Control and Prevention (CDC). National Center for Health Statistics. Deaths: Final data for 2009. Natl Vital Stat Rep. 2011; 60(03):1-117.

2. Agency for Healthcare Research and Quality. HCUPnet: Online query system based on data from the Healthcare Cost and Utilization Project. HCUPnet website. http://hcupnet.ahrq.gov. Accessed August 52014.

3. Jencks SF, Williams MV, Coleman EA. Rehospitalizations among patients in the medicare fee-for-service program. $N$ Engl J Med. 2009;360:1418-1428.

doi: http://dx.doi.org/10.1056/NEJMsa0803563

4. National Heart Lung and Blood Institute Fact Book, Fiscal Year 2012, Chapter 4-Disease statistics. National Heart Lung and Blood Institute website. http://www.nhlbi.nih.gov/about/factbook/ chapter4.htm. Published 2012. Accessed August 52014.

5. Stein BD, Charbeneau JT, Lee TA, et al. Hospitalizations for acute exacerbations of chronic obstructive pulmonary disease: How you count matters. COPD. 2010;7:164-171. doi: http://dx.doi.org/10.3109/15412555.2010.481696

6. Medicare Payment Advisory Commission. Report to the Congress: Promoting Greater Efficiency in Medicare. Washington, DC: Medicare Payment Advisory Commission; 2007.

7. Toy EL, Gallagher KF, Stanley EL, Swensen AR, Duh MS. The economic impact of exacerbations of chronic obstructive pulmonary disease and exacerbation definition: a review. COPD. 2010; 7: 214-228.

doi: http://dx.doi.org/10.3109/15412555.2010.481697

8. Lindenauer PK, Pekow P, Gao S, Crawford AS, Gutierrez B, Benjamin EM. Quality of care for patients hospitalized for acute exacerbations of chronic obstructive pulmonary disease. Ann Intern Med. 2006; 144:894-903. Doi: http://dx.doi. org/10.7326/0003-4819-144-12-200606200-00006

9. Boston University Medical Center, Boston University School of Medicine. Project Red (Re-Engineered Discharge) website. http://www.bu.edu/fammed/projectred/index.html. Published 2014. Accessed August 5, 2014.

10. Penn Nursing Science.Transitional Care Model website. http:// www.transitionalcare.info/. Accessed August 5, 2014.

11. School of Medicine Health Care Policy and Research, University of Colorado, Anschultz Medical Campus. The Care Transitions Program website. http://www.caretransitions.org/documents/ Evidence_and_Adoptions_9_2014.pdf Accessed December 12, 2014

12. Project Boost mentored implementation program. Society of Hospital Medicine website. http://www.hospitalmedicine.org/ boost/. Accessed August 5, 2014.

13. Mularski RA, McBurnie MA, Lindenauer PK, et al. CONCERT Investigator Consortium. Comparative effectiveness research in chronic obstructive pulmonary disease. J Comp Eff Res. 2012; 1:71-82. doi: http://dx.doi.org/10.2217/cer.11.10

14. Lindenauer PK, Grosso LM, Wang C, et al. Development, validation, and results of a risk-standardized measure of hospital 30-day mortality for patients with exacerbation of chronic obstructive pulmonary disease. J Hosp Med. 2013; 8:428-35. doi: http://dx.doi.org/10.1002/jhm.2066
15. Mularski RA, Asch SM, Shrank WH, et al. The quality of obstructive lung disease care for adults in the United States as measured by adherence to recommended processes. Chest. 2006; 130: 1844-1850. doi: http://dx.doi.org/10.1378/chest.130.6.1844

16. Elixhauser A, Au DH, Podulka J. Readmissions for Chronic Obstructive Pulmonary Disease, 2008: Statistical Brief \#121. In: Healthcare Cost and Utilization Project (HCUP) Statistical Briefs. Rockville, MD: Agency for Health Care Policy and Research; 2006. http://www.ncbi.nlm.nih.gov/books/NBK65392/. Accessed August 5,2014

17. Hurst JR, Vestbo J, Anzueto A, et al. Susceptibility to exacerbation in chronic obstructive pulmonary disease. $N$ Eng J Med. 2010; 363:1128-38.

doi: http://dx.doi.org/10.1056/NEJMoa0909883

18. Barr RG, Celli BR, Mannino DM, et al. Comorbidities, patient knowledge and disease management in a national sample of patients with chronic obstructive pulmonary disease. Am J Med. 2009; 122(4):348-355.

doi: http://dx.doi.org/10.1016/j.amjmed.2008.09.042

19. Schnell KM, Weiss CO, Lee TA, et al. The prevalence of clinically-relevant comorbid conditions in patients with COPD: a cross-sectional study using data from NHANES 1999-2008. BMC Pulm Med. 2012; 12:26.

doi: http://dx.doi.org/10.1186/1471-2466-12-26

20. Baker CL, Zou KH, Su J. Risk assessment of readmissions following an initial COPD-related hospitalization. Int $J$ Chron Obstruct Pulmon Dis. 2013; 2013:551-559.

21. Charlson M, Charlson RE, Briggs W, Hollenberg J. Can disease management target patients most likely to generate high costs? The impact of comorbidity. J Gen Intern Med. 2007; 22(4):464469. doi: http://dx.doi.org/10.1007/s11606-007-0130-7

22. Divo M, Cote C, Casanova C, et al. Comorbidities and risk of mortality in patients with COPD. Am J Resp Crit Care Med. 2012; 186(2):155-161. doi:http://dx.doi.org/10.1164/rccm.201201-0034OC

23. Budweiser S, Harlacher M, Pfeifer M. Jorres RA. Co-morbidities and hyperinflation are independent risk factors of all-cause mortality in very severe COPD. COPD. 2014; 11(4):388-400. doi: http://dx.doi.org/10.3109/15412555.2013.836174

24. Mannino DM, Buist AS, Petty TL, Enright PL, Redd SC. Lung function and mortality in the United States: data from the first National Health and Nutrition Examination Study follow-up study. Thorax. 2003; 58:388-393. doi: http://dx.doi.org/10.1136/thorax.58.5.388

25. Krumholz HM. Post-hospital syndrome: An acquired, transient condition of generalized risk. N Engl J Med. 2013; 368:100-102. doi: http://dx.doi.org/10.1056/NEJMp1212324

26. Spencer S, Karner C, Cates CJ, Evans DJ. Inhaled corticosteroids versus long-acting beta 2-agonists for chronic obstructive pulmonary disease. Cochrane Database Syst Rev. 2011, (12). doi: http://dx.doi.org/10.1002/14651858.CD007033.pub3

27. Vincken W, van Noord JA, Greefhorst AP, et al for the Dutch/ Belgian Tiotropium Study Group. Improved health outcomes in patients with COPD during 1 yr's treatment with tiotropium. Eur Respir J. 2002; 19:209-16.

doi: http://dx.doi.org/10.1183/09031936.02.00238702 
28. Poole PJ, Black PN. Mucolytic agents for chronic bronchitis or chronic obstructive pulmonary disease. Cochrane Database Syst Rev. 2006;(3).

29. Seemungal T, Wilkinson TMA, Hurst JR, Perera W, Sapsford RJ, Wedzicha JA. Long term macrolide therapy is associated with decreased COPD exacerbation frequency. Am J Respir Crit Care Med. 2008; 178(11):1139-1147.

doi: http://dx.doi.org/10.1164/rccm.200801-1450C

30. Melani AS, Bonavia M, Cilenti V, et al. Inhaler mishandling remains common in real life and is associated with reduced disease control. Respir Med. 2011;105(6):930-938. doi: http://dx.doi.org/10.1016/j.rmed.2011.01.005

31. Press VG, Arora VM, Shah LM, et al. Misuse of respiratory inhalers in hospitalized patients with asthma or COPD. J Gen Intern Med. 2011; 26(6):635-642. doi: http://dx.doi.org/10.1007/s11606-010-1624-2

32. Yawn BP, Colice GL, Hodder R. Practical aspects of inhaler use in the management of chronic obstructive pulmonary disease in the primary care setting. Int J Chron Obstruct Pulmon Dis. 2012; 2012:495-502. doi: http://dx.doi.org/10.2147/COPD.S32674

33. Neri M, Melani AS, Miorelli AM, et al. Long-term oxygen therapy in chronic respiratory failure: a Multicenter Italian Study on Oxygen Therapy Adherence (MISOTA). Respir Med. 2006; 100(5):795-806. doi: http://dx.doi.org/10.1016/j.rmed.2005.09.018

34. Robinson T. Living with severe hypoxic COPD: the patients' experience. Nurs Times. 2005; 101(7):38-42.

35. Crockett AJ, Cranston JM, Moss JR, Alpers JH. Effects of longterm oxygen therapy on quality of life and survival in chronic airflow limitation. Monaldi Arch Chest Dis. 1999; 54:193-196.

36. Block AJ, Castle JR, Keitt AS. Chronic oxygen therapy. Treatment of chronic obstructive pulmonary disease at sea level. Chest. 1974; 65(3):279-288.

doi: http://dx.doi.org/10.1378/chest.65.3.279

37. Leggett RJ, Flenley DC. Portable oxygen and exercise tolerance in patients with chronic hypoxic cor pulmonale. $\mathrm{Br}$ Med J. 1977, 2:84-86. doi: http://dx.doi.org/10.1136/bmj.2.6079.84

38. Desveaux L, Ferreira TJ, Goldstein R, Brooks D. An international comparison of pulmonary rehabilitation: a systematic review. COPD. 2014. [Epub ahead of print].

doi: http://dx.doi.org/10.3109/15412555.2014.922066

39. Suh ES, Mandal S, Hart N. Admission prevention in COPD: nonpharmacological management. BMC Med. 2013;11:247. doi: http://dx.doi.org/10.1186/1741-7015-11-247

40. Schauer GL, Wheaton AG, Malarcher AM, Croft JB. Smoking prevalence and cessation characteristics among U.S. adults with and without COPD: Findings from the 2011 Behavioral Risk Factor Surveillance System. COPD. 2014; 11(6):697-704. doi: http://dx.doi.org/10.3109/15412555.2014.898049

41. Anthonisen NR, Connett JE, Enright PL, Manfreda J. Hospitalizations and mortality in the lung health study. Am J Respir Crit Care Med. 2002; 166(3):333-339. doi: http://dx.doi.org/10.1164/rccm.2110093

42. Kessler R, Faller M, Fourgaut G, Mennecier B, Weitzenblum E. Predictive factors of hospitalization for acute exacerbation in a series of 64 patients with chronic obstructive pulmonary disease. Am J Respir Crit Care Med. 1999; 159(1):158-164. doi: http://dx.doi.org/10.1164/ajrccm.159.1.9803117
43. Godtfredsen NS, Vestbo J, Osler M, Prescott E. Risk of hospital admission for COPD following smoking cessation and reduction: a Danish population study. Thorax. 2002; 57:967-972. doi: http://dx.doi.org/10.1136/thorax.57.11.967

44. Au DH, Bryson CL, Chien JW, et al. The effects of smoking cessation on the risk of chronic obstructive pulmonary disease exacerbations. J Gen Intern Med. 2009; 24(4):457-463. doi: http://dx.doi.org/10.1007/s11606-009-0907-y

45. Schembri S, Anderson W, Morant S, et al. A predictive model of hospitalisation and death from chronic obstructive pulmonary disease. Respir Med. 2009; 103(10):1461-1467. doi: http://dx.doi.org/10.1016/j.rmed.2009.04.021

46. Schembri S, Morant S, Winter JH, MacDonald TM. Influenza but not pneumococcal vaccination protects against all-cause mortality in patients with COPD. Thorax. 2009; 64:567-72. doi: http://dx.doi.org/10.1136/thx.2008.106286

47. Plans-Rubió P. Prevention and control of influenza in persons with chronic obstructive pulmonary disease. Int $J$ Chron Obstruct Pulmon Dis. 2007; 2:41-53. doi: http://dx.doi.org/10.2147/copd.2007.2.1.41

48. Kangovi S, Grande D. Hospital readmissions--not just a measure of quality. JAMA. 2011; 306 (16):1796-1797. doi: http://dx.doi.org/10.1001/jama.2011.1562

49. Calvillo-King L, Arnold D, Eubank KJ, et al. Impact of social factors on risk of readmission or mortality in pneumonia and heart failure: Systematic review. J Gen Intern Med. 2013; 28(2):269-282. doi: http://dx.doi.org/10.1007/s11606-012-2235-x

50. Prieto-Centurion V, Gussin HA, Rolle AJ, Krishnan JA. Chronic obstructive pulmonary disease readmissions at minority-serving institutions. Ann Am Thorac Soc. 2013; 10(6):680-684. doi: http://dx.doi.org/10.1513/AnnalsATS.201307-223OT

51. Readmissions reduction program. Centers for Medicare and Medicaid Services website. http://www.cms.gov/Medicare/ Medicare-Fee-for-Service-Payment/AcuteInpatientPPS/ Readmissions-Reduction-Program.html. Updated August 2014. Accessed August 5, 2014

52. Feemster LC, Au DH. Penalizing hospitals for chronic obstructive pulmonary disease readmissions. Am J Resp Crit Care Med. 2014; 189 (6): 634-639.

doi: http://dx.doi.org/10.1164/rccm.201308-1541PP

53. Kangovi S, Grande D. Transitional care management reimbursement to reduce COPD readmission. Chest. 2014; 145(1):149-155. doi: http://dx.doi.org/10.1378/chest.13-0787

54. Stein BD, Bautista A, Schumock GT, et al. The validity of International Classification of Diseases, Ninth Revision, Clinical Modification diagnosis codes for identifying patients hospitalized for COPD exacerbations. Chest. 2012; 141(1):87-93. doi: http://dx.doi.org/10.1378/chest.11-0024

55. Hansen LO, Young RS, Hinami K, Leung A, Williams MV. Interventions to reduce 30-day rehospitalization: A systematic review. Ann Intern Med. 2011; 155(8):520-528. doi: http://dx.doi.org/10.7326/0003-4819-155-8-201110180-00008

56. Jack BW, Chetty VK, Anthony D, et al. A reengineered hospital discharge program to decrease rehospitalization: a randomized trial. Ann Intern Med. 2009; 150(3):178-87. doi: http://dx.doi.org/ 10.7326/0003-4819-150-3-200902030-00007 
57. Coleman EA, Parry C, Chalmers S, Min SJ. The Care Transitions Intervention. Results of a randomized controlled trial. Arch Intern Med. 2006; 166(17): 1822-28. doi: http://dx.doi.org/10.1001/archinte.166.17.1822

58. Coleman EA, Smith JD, Frank JC, Min S, Parry C, Kramer AM. Preparing patients and caregivers to participate in care delivered across settings: the care transitions intervention. $J$ Am Geriatr Soc. 2004; 52(11):1817-1825. doi: http://dx.doi.org/10.1111/j.1532-5415.2004.52504.x

59. Parry C, Kramer H, Coleman EA. A qualitative exploration of a patient-centered coaching intervention to improve care transitions in chronically ill older adults. Home Health Care Serv Q. 2006; 25(3-4):39-53. doi: http://dx.doi.org/10.1300/J027v25n03_03

60. Naylor MD, Brooten D, Campbell R, et al. Comprehensive discharge planning and home follow-up of hospitalized elders: a randomized clinical trial. JAMA. 1999; 281(7):613-620. doi: http://dx.doi.org/10.1001/jama.281.7.613

61. Naylor MD, Brooten DA, Campbell RL, Maislin G, McCauley KM, Schwartz JS. Transitional care of older adults hospitalized with heart failure: a randomized, controlled trial. J Am Geriatr Soc. 2004; 52(5):675-684. doi: http://dx.doi.org/10.1111/j.1532-5415.2004.52202.x

62. Maynard G, Budnitz T, Nickel WK, et al. Mentored implementation: a collaborative improvement model for breakthrough achievement. Jt. Comm J Qual Saf. 2012; 38:301-10.

63. Coleman EA, Williams MV. Executing high-quality care transitions: a call to do it right. J Hosp Med. 2007; 2(5):287-290. doi: http://dx.doi.org/10.1002/jhm.276

64. Williams MV, Coleman EA. BOOSTing the hospital discharge. $J$ Hosp Med. 2009; 4(4):209-210. doi: http://dx.doi.org/10.1002/jhm.525

65. Hansen LO, Greenwald JL, Budnitz T, et al. Project BOOST: Effectiveness of a multihospital effort to reduce rehospitalization. J Hosp Med. 2013; 8(8):421-427. doi: http://dx.doi.org/10.1002/jhm.2054

66. Markley J, Andow V, Sabharwal K, Wang Z, Fennell E, Dusek R. A project to reengineer discharges reduces 30-day readmission rates. Am J Nurs. 2013; 113(7):55-64. doi: http://dx.doi.org/10.1097/01.NAJ.0000431922.47547.eb

67. Naylor M, Brooten D, Jones R, Lavizzo-Mourey R, Mezey M, Pauly M. Comprehensive discharge planning for the hospitalized elderly: a randomized clinical trial. Ann Intern Med. 1994; 120(12):999-1006. doi: http://dx.doi.org/10.7326/00034819-120-12-199406150-00005

68. Naylor MD, Hirschman KB, Hanlon AL, et al. Comparison of evidence-based interventions on outcomes of hospitalized, cognitively impaired older adults. J Comp Eff Res. 2014; 3(3):245257. doi: http://dx.doi.org/10.2217/cer.14.14

69. Parry C, Coleman EA, Smith JD, Frank JC, Kramer AM. The Care Transitions Intervention: A patient-centered approach to facilitating effective transfers between sites of geriatric care. Home Health Serv Q. 2003; 22(3):1-18. doi: http://dx.doi.org/10.1300/J027v22n03_01
70. Prieto-Centurion V, Markos MA, Ramey NI, et al. Interventions to reduce rehospitalizations following COPD exacerbations: a systematic review. Ann Am Thorac Soc. 2014; 11(3):417-424. doi: http://dx.doi.org/10.1513/AnnalsATS.201308-254OC

71. Fan VS, Gaziano JM, Lew R, et al. A comprehensive care management program to prevent chronic obstructive pulmonary disease hospitalizations: A randomized, controlled trial. Ann Intern Med. 2012; 156(10):673-683. doi: http://dx.doi. org/10.7326/0003-4819-156-10-201205150-00003

72. Casas A, Troosters T, Garcia-Aymerich J, et al. Integrated care prevents hospitalisations for exacerbations in COPD patients. Eur Resp J. 2006; 28(1):123-130. doi: http://dx.doi.org/10.1183/09031936.06.00063205

73. Kwok T, Lum CM, Chan HS, Ma HM, Lee D, Woo J. A randomized, controlled trial of an intensive community nurse-supported discharge program in preventing hospital readmissions of older patients with chronic lung disease. J Am Geriatr Soc. 2004; 52(8):1240-1246. doi: http://dx.doi.org/10.1111/j.1532-5415.2004.52351.x

74. Bourbeau J, Julien M, Maltais F, et al. Reduction of hospital utilization in patients with chronic obstructive pulmonary disease: A disease-specific self-management intervention. Arch Intern Med. 2003; 163(5):585-591. doi: http://dx.doi.org/10.1001/archinte.163.5.585

75. Bucknall CE, Miller G, Lloyd SM, et al. Glasgow supported selfmanagement trial (GSuST) for patients with moderate to severe COPD: Randomised controlled trial. Br Med J. 2012;344:e1060. doi: http://dx.doi.org/10.1136/bmj.e1060

76. Kanel KT, Elster S, Vrbin C. PRHI readmission brief: chronic obstructive pulmonary disease. Pittsburgh Regional Health Initiative website. http://www.prhi.org/images/stories/docs/ PRHI\%20COPD\%20Readmission\%20Brief\%20Dec\%202011. pdf. Accessed August 5, 2014. 